\title{
Jornalismo hiperlocal e internet: a comunicação hiperlocal cidadã como possibilidade na arena pública
}

\author{
Hyperlocal journalism and internet: hyperlocal citizen communication as a \\ possibility in the public arena \\ Periodismo hiperlocal e internet: la comunicación hiperlocal ciudadana como \\ posibilidad en la arena pública \\ Antonio Francisco Magnoni ${ }^{1}$ \\ Giovani Vieira Miranda ${ }^{2}$
}

\begin{abstract}
Resumo
O presente texto sugere uma discussão sobre as reconfigurações pelas quais passa o campo do jornalismo a partir da inserção de tecnologias móveis e ubíquas e, mais especificamente, as mídias locativas e suas funções e serviços no dia-dia dos cidadãos. As análises servirão de preâmbulo para a discussão sobre o novo cenário hiperlocal no qual está inserido o processo de construção do jornalismo com direção para novos panoramas no meio digital e suas implicações em nível local. Para tanto, também será debatida a aproximação do jornalismo hiperlocal como arena pública; levando em consideração a ambiência da inclusividade, não coerção e reciprocidade que dão potencial para a promoção de um espaço de debate entre múltiplas vozes da sociedade, sobre os mais diferentes assuntos; considerando um fluxo de informação que propicie a consolidação das opiniões públicas e o incentivo ao debate público em nível local.
\end{abstract}

Palavras-chave: Mídias locativas. Jornalismo hiperlocal. Arena pública. Comunicação local.

\begin{abstract}
The present text suggests a discussion about the reconfigurations through which the area of journalism passes from the insertion of mobile and ubiquitous technologies and, more specifically, the locative media and its functions and services geolocalized in the day to day of the citizens. The analysis will serve as a preamble for the discussion about the new hyperlocal scenario in which the process of building journalism with direction for new panoramas in the digital environment and its implications at the local level is inserted. Therefore, the approach of hyperlocal journalism as a public arena will also be debated; taking into account the ambience of inclusiveness, non-coercion and reciprocity that give potential for the promotion of a space for debate among the many voices of society on different subjects; considering a flow of information that promotes the consolidation of public opinions and the encouragement of public debate at the local level.
\end{abstract}

Keywords: Locative media. Hyperlocal journalism. Public arena. Local communication.

\section{Resumen}

El presente texto sugiere una discusión sobre las reconfiguraciones a través de las cuales pasa el área de periodismo desde la inserción de tecnologías móviles y ubicuas y, más específicamente, los medios locativos y sus funciones y servicios geolocalizados en el día a día de los ciudadanos. El análisis servirá como un preámbulo para la discusión sobre el nuevo escenario hiperlocal en el cual se inserta el proceso de construir periodismo con dirección para panoramas nuevos en el entorno digital y sus implicaciones a nivel local. Por lo tanto, el enfoque del periodismo hiperlocal como escenario público

\footnotetext{
${ }^{1}$ Doutor em Educação, Professor no Programa de Pós-Graduação em Mídia e Tecnologia, líder do Grupo de Estudos GEMS (Games, Educação, Mídia e Sentido) - Universidade Estadual Paulista Unesp/Bauru. e-mail: afmagnoni@gmail.com

${ }^{2}$ Doutorando pelo Programa de Pós-Graduação em Mídia e Tecnologia da FAAC Unpes/Bauru. Brasil. e-mail: contato@giovanimiranda.com.
}

Comun. \& Inf., Goiânia, GO, v. 21, n. 3, p. 166-184, out./dez. 2018. 
también será debatido; tomando en cuenta el ambiente de inclusión, no coacción y reciprocidad que dan potencial para la promoción de un espacio de debate entre las muchas voces de la sociedad sobre diferentes temas; considerando un flujo de información que promueve la consolidación de las opiniones públicas y el estímulo del debate público a nivel local.

Palabras-clave: Medios locativos. Periodismo hiperlocal. Arena pública. Comunicación local.

\section{INTRODUÇÃO}

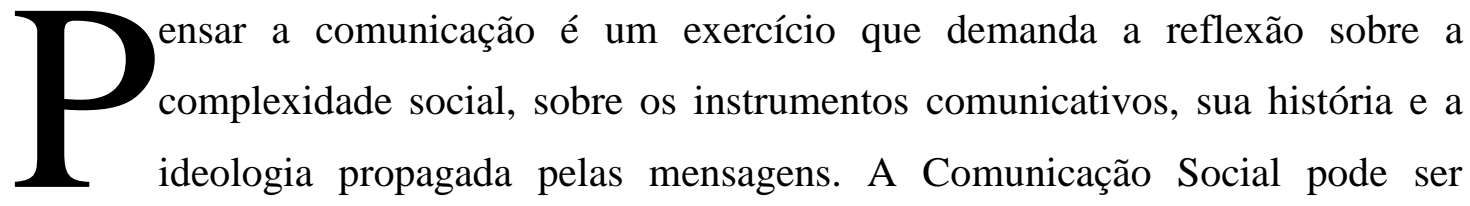
dimensionada em uma intersecção da ideia de formação de opinião e das transformações sociais pelas quais passaram a sociedade. A mudança estrutural da Esfera Pública discutida inicialmente por Habermas (1997), fez com que fosse destacado tal ponto, desde a concepção de cidadania nas ágoras atenienses até as atuais questões de publicização dos fatos, sem deixar de considerar o importante papel desempenhado pela mídia nesse processo.

Para Habermas (1997), entre as funções ideais desempenhadas pela mídia em sistemas políticos considerados constitucionais está o ato de vigiar sobre o ambiente sociopolítico; definir as questões significativas da agenda política; estabelecer canais/plataformas que possibilitam o processo de defesa das posições; permitir o diálogo e o debate entre os diversos pontos de vista; a criação de mecanismos para a prestação pública das contas; incentivar os cidadãos e convidá-los à participação ativa; resistir a todo processo que vise restringir o aspecto do debate público; e o respeito de todos os envolvidos.

Usualmente, no entanto, o fluxo da informação é constituído por diversos mecanismos que filtram a informação. Os critérios de noticiabilidade não são os únicos vetores que determinam o conteúdo. Há aspectos técnicos, éticos, editoriais, ideológicos e políticos (MORAES; RAMONET; SERRANO, 2013). A observação do fato, a negociação entre os grupos que constituem o processo produtivo, a convergência/divergência com a política editorial do veículo, as cadeias de comando horizontais e verticais, e os interesses comerciais das empresas transformam a pauta, muitas vezes, em mera referência burocrática, para a produção do conteúdo. O processo industrial da informação tem afetado as condições de trabalho dos jornalistas e contribui com a transformação do conteúdo (RIBEIRO, 1994).

Nesse processo, não há uma discussão aberta na Esfera Pública de forma que as deliberações são apenas repassadas à sociedade, contrariando o ideal republicano democrático de autogoverno dos cidadãos (VIZEU; ROCHA; MESQUITA, 2010). 
O resultado da ausência de discussões abertas e da permanência de meios de comunicação que restringem o debate público, priva a esfera pública do debate de temas de interesse social. O procedimento de empacotamento do conteúdo é condicionado por critérios que impõe a submissão de um tema em relação a outro. O relevo, a proximidade, o impacto da notícia submete outros tópicos de interesse, e articulam uma narrativa única das notícias, com a inclusão/exclusão de assuntos de relevância pública. A discordância desses temas com a realidade factual provoca distorção na informação. Esse artifício tira da esfera pública de debate teses fundamentais para a compreensão da realidade social, e reduz a capacidade da cidadania de superá-los (KOVACH; ROSENSTIEL, 2003).

A ideia de um mundo emancipado como previsto por Habermas (1984), no qual se há a valoração do debate crítico-racional-reflexivo se esbarra diante do processo de mudança estrutural da Esfera Pública em um ciclo de produção e consumo, partindo para um processo de simplificação e alienação.

Nesse sentido, como aponta Marcondes (2007), tais mudanças na Esfera pública acabam por prejudicar o processo de reflexão crítica, sendo a razão substituída pela distração e pelo consumo. "A extinção da crítica na Esfera Pública contribui para a anulação das capacidades políticas do homem e, em consequência, para o abuso de poder e a manipulação das massas" (MARCONDES, 2007, s/p). Para Dourado (2013), as informações passam a ser visualizadas como mercadorias que serão comercializadas diante de um processo de espetacularização, sem aprofundamento crítico ou maior elaboração dos processos produtivos, dos acontecimentos que buscam atingir o maior número de pessoas.

As redações adotam políticas de objetividade e imparcialidade que, mesmo impossíveis de serem atingidas, levam à fragmentação, à superficialidade, ao enxugamento da interpretação, à despolitização e à visualidade em detrimento do conteúdo. Ao invés de intermediar a opinião pública, os meios de comunicação desenvolvem técnicas para moldá-la a seu modo (DOURADO, 2013, p. 3-4).

Por outro lado, na atual estrutura, enquanto se ressalta um espaço público midiático restrito, há um processo emergente de reconfiguração da Esfera Pública, associada à criação de outras mídias (RAMOS; SANTOS, 2007). A partir do uso cada vez mais corriqueiro das tecnologias da comunicação e da informação, emergiu nas últimas décadas "uma nova revolução nas relações de poder", em especial no campo das comunicações que "tornou possível as condições materiais de imposição de um mesmo discurso à escala planetária, com 


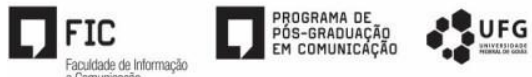

o estabelecimento de um verdadeiro oligopólio mundial das fontes emissoras de comunicação" (PORTO-GONÇALVES, 2004, p. 16).

O debate público foi ampliado com as possibilidades de comunicação vindas com a ascensão da internet. Passaram a existir outras formas efetivas de divulgação dos conteúdos críticos e reflexivos que são de interesse público, com a possibilidade de se fazer uma análise da própria mídia e publicizar uma visão considerada alternativa. De acordo com Leal (2013), tem início um processo capaz de revalorizar o espaço público e criar a sensação de maior representação da opinião pública, com um potencial de ativar novas práticas sociais e políticas que vão fazer força de resistência às antigas possibilidades até então convencionadas. Com isso, há uma significativa abertura para a participação individual e à cidadania, ambas com potencial amplificado a partir das novas ferramentas e possibilidades de fluxo de produção e interação vindos com a internet.

De certa forma, isso promove a reconfiguração do espaço público "diminuindo a crise subjetiva e intersubjetiva de sentido alimentada pela tendência à alienação e anomia que se verifica na modernidade" (VIZEU; ROCHA; MESQUITA, 2010) a partir do reconhecimento de que o cidadão tem o direito de participar do fluxo de construção de sentido e da construção social da realidade, com um aumento, por consequência, do engajamento cívico.

\section{EM CENA A COMUNICAÇÃO HIPERLOCAL}

O hiperlocal começou a ser usado para referir-se a cobertura de notícias em nível de comunidade geralmente esquecidas pela mídia tradicional, sendo inclusive, trazida para o contexto das produções online.

A comunicação hiperlocal se concentra na cobertura de eventos de uma área geográfica específica: um bairro, uma cidade ou mesmo um Estado, embora os cidadãos que possam vir a discutir ou relatar o evento online possa estar fora dessa mesma área geográfica. Apesar do cenário globalizado, Barbosa (2003) lembra que as informações de caráter local também sempre foram de grande relevância para o jornalismo. Entretanto, a novidade é que a estrutura das redes no jornalismo digital "permite novas possibilidades para a geração dos conteúdos locais, ampliando o espaço para a sua veiculação" (BARBOSA, 2013, p. 1).

Metzgar et al (2010) destacam a comunicação hiperlocal cidadã como aquela que incide sobre histórias locais em contraponto a narrativas globais; podendo ser produzida a partir das organizações noticiosas estabelecidas ou por meio daqueles que não estão inseridos em um contexto de produção e de disseminação do conteúdo. 
Operações de mídia Hiperlocal são geograficamente baseadas, voltadas para a comunidade, organizações nativas e originais em reportar notícias para a web e pretendem preencher as lacunas percebidas na cobertura de uma questão ou região e promovem o engajamento cívico (METZGAR et al, 2010, p. 7).

Para López García (2002), a comunicação local interpreta a realidade pela ótica dos valores compartilhados e tem contribuído para a personificação de um cenário da comunicação atual, onde a dupla e simultânea tendência do local e do global apresenta novos recursos, cujas referências dos comunicantes são extraídas das duas esferas, que são complementares durante as ações comunicativas. No âmbito do jornalismo digital, o local pode ser compreendido a partir da sobrevivência dos antigos modelos, em conjunto com as apostas e recursos midiáticos mais modernos, o que faz com que a informação gerada no nível hiperlocal seja de maior qualidade, mais plural e mais participativa, de forma que "explique o que acontece no âmbito onde está sediado o veículo de comunicação, para quem informa e que narre o que afeta e interessa os habitantes desse território espacial, inclusive, quando se produz fora" (LÓPEZ GARCÍA, 2002, p. 34).

Lemos (2011) aponta a produção de notícias em âmbito digital localizado como uma conjunção de funções pós-massivas e massivas, onde o usuário pode ter informações mais precisas sobre o seu local de interesse a partir de um cruzamento de notícias.

A dimensão hiperlocal no jornalismo (já que ele é sempre local) refere-se, em primeiro lugar, a informações que são oferecidas em função da localização do usuário (sobre o bairro, a rua, etc.), e em segundo lugar, pelas características pós-massivas desse novo jornalismo onde qualquer um pode ser produtor de informação. Essa é uma das tendências atuais do jornalismo: vinculação de notícias cruzando diversas fontes, oficiais, profissionais e cidadãs à geolocalização (LEMOS, 2011, p.12).

A partir desse entendimento, pode-se observar a aproximação das práticas do jornalismo hiperlocal com as do jornalismo cidadão, em especial no que se refere ao envolvimento das comunidades e suas organizações com relação aos problemas sociais, econômicos e ambientais urbanos que enfrentam e, sistematicamente, não são noticiados ou são mal noticiados pelo jornalismo tradicional.

\section{EXEMPLO HIPERLOCAL EM BAURU, INTERIOR DE SP}

Entendendo que "a Esfera Pública política precisa de recursos fornecidos pelos cidadãos que dão voz aos problemas da sociedade e que respondem às questões articuladas 
pelo discurso da elite" (HABERMAS, 1984), bem como a noção da mídia hiperlocal cidadã como um espaço para a consolidação de uma microesfera Pública no debate democrático, o presente tem por corpus o blogue Mafuá do PHA, de Bauru, interior do Estado de São Paulo. A abordagem será baseada no estudo de caso descritivo, pois opta por explorar, descrever e explicar um fenômeno atual em seu contexto a partir de uma fonte de análise considerando o fenômeno em um contexto de construção social.

A escolha pelo blogue deveu-se em primeiro lugar ao interesse pelo uso da ferramenta como um meio de comunicação para a propagação de conteúdos de nível local. Bauru destaca-se por iniciativas privadas de comunicação em rádio, televisão e jornais e com raros casos de mídia independente ou com características cidadãs. Com esse caso, pretendeu-se sugerir relações entre as características dos diferentes modelos de comunicação de massa (e das estruturas nacionais nas quais estão inseridos) com a constituição de microesferas públicas mais firmemente apoiadas em práticas democráticas, cidadãs e plurais; analisar e identificar os meios hiperlocais cidadãos como possíveis microesferas públicas e avaliar em que medida os meios hiperlocais favorecem o incremento da participação de diferentes atores e grupos sociais. Sobre a origem do mafuá, Henrique destaca que o mantém com a intenção de escrever sobre as histórias da cidade sob um recorte histórico e também jornalístico.

$\mathrm{Na}$ ânsia de escrever e ciente de quem nem tudo pode ser publicado pela aí [sic], criei o mafuá. Nesses anos todos acredito ter conquistado algo de bom, ajudei muitos e a maior alegria que tenho é quando cruzo com alguém e esse me diz: Te sigo (AQUINO, 2016) ${ }^{3}$.

Em termos de layout, considerando a estrutura e a organização da informação, o formato da página inicial do Mafuá do HPA é simples, com o uso de poucos recursos que não sejam o textual e a utilização de imagens, com um layout gratuito do Blogger, serviço gratuito oferecido pelo Google com ferramentas de edição e gerenciamento de blogues, sem nenhum tipo de alteração e inserção de outros elementos que hoje já são disponibilizados para personalizar a estrutura do mesmo. Quando indagado sobre o porquê da simplicidade do blogue, o autor revela que a mantém por opção e também por desconhecer as possibilidades da plataforma escolhida, e ressalta que para ele o Mafuá não terá objetivos comerciais e manterá as suas características de simplicidade como elemento de aproximação com os seus leitores.

\footnotetext{
${ }^{3}$ Entrevista concedida a este autor no dia 18 de maio de 2016.
} 
Nunca imaginei ganhar grana com o que faço e nem acho que alguém iria investir no modelo que prático [sic], com cutucões a torto e a direito. Perceba que mantenho a mesma página de abertura desde o começo e não mudei por não saber como alterar. Podia até mudar, mas se está bom assim, penso sempre duas vezes e tudo continua como dantes. A simplicidade é o que me move. Não sou um cara de salamaleques e rococós. Blog para mim é isso, pelo menos o meu eu quero que ele tenha a minha cara e acredito que o mafuá [sic] tenha (AQUINO, 2016) ${ }^{4}$.

Com isso, o autor afirma que em sua visão a liberdade editorial está distante de interesses comerciais. Sendo assim, ele acredita que a monetização do conteúdo, aqui no sentido de venda de espaço publicitário, afetaria a produção do blogue no ponto de significar interferência e extinção na personalidade até então adquirida.

Mesmo refutando quaisquer tipos de mudança, o autor não deixa de considerar possíveis modificações, desde que haja um auxílio externo com a ferramenta e para eventuais sugestões de mudanças:

Muitos me chamam na rua de "Mafuá" e não vejo demérito nisso. Para mim é até uma forma legal de reconhecimento. Não sei até quando vai perdurar esse modelo de blog livres e com custo livre na internet. Vou tocando o barco ao meu modo e jeito, sem grandes compromissos. [...] E assim, toco o barco, piso no acelerador e a coisa continua, sem grandes arroubos e quase nada de modernidade. Prometo que um dia aprendo algo novo e incremento o blog, mas me falta tempo, pois minha vida é bater escanteio e correr para fazer gol (AQUINO, 2016) ${ }^{5}$.

Logo na página inicial, as informações são disponibilizadas de maneira simples, sendo divididas em duas colunas básicas. Na da direita, é possível ter acesso aos perfis dos usuários dos recursos do Google que optaram por seguir o blogue, em um total de 248 seguidores $^{6}$, com todo o histórico disponibilizado logo abaixo.

Em um único local, é possível ter acesso a toda a memória do blogue desde setembro de 2007 , em um total de 3528 postagens $^{7}$ divididas por assuntos, organizadas em meses do ano e agrupadas em seus respectivos anos. Os posts estão visíveis por ordem de atualização, isto é, seguem a ordem decrescente de publicação com os conteúdos mais recentes sendo listados no topo. Esta é uma forma de organização básica adotada por blogues mais simples que buscam conceder ao visitante da página um acesso mais rápido à informação postada. Logo após o arquivo do blogue, segue-se uma apresentação do cidadão blogueiro acompanhada por uma página e da sucinta proposta da página.

\footnotetext{
${ }^{4}$ Entrevista concedida a este autor no dia 18 de maio de 2016.

${ }^{5}$ Entrevista concedida a este autor no dia 18 de maio de 2016.

${ }^{6}$ Informação atualizada em 10 de outubro de 2017.

${ }^{7}$ Informação atualizada em 10 de outubro de 2017.
} 
Já na coluna da direita, ficam disponibilizadas as postagens para a leitura na íntegra, em um total de sete. Todas as postagens do Mafuá também são disponibilizadas em sua totalidade no perfil pessoal do blogueiro cidadão responsável na rede social Facebook $^{8}$

Mesmo que não haja uma divisão dos conteúdos por categorias ou mesmo editorias, o blogueiro cidadão acaba por criar espaços com ideias de postagens semelhantes, tais como "Memória Oral" (postagens utilizadas para contar passagens históricas da cidade); "Lado B de Bauru" (espaço destinada para focar personagens e fatos que não figuram na chamada mídia massiva de Bauru), "Personagens sem carimbo" (foco em anônimos das comunidades da cidade e suas histórias de vida), "Bauru Por aí" (relatos sobre fatos pontuais da cidade), entre outras.

A produção inédita dos conteúdos não segue os critérios jornalísticos, sendo o fluxo definido a partir de modos subjetivos do próprio autor, sendo preferidos os "assuntos mais simples" e com uma ótica que destoa dos demais meios de comunicação da cidade, essencialmente pelo fato de destacar temas e figuras que não ganham a pauta desse:

Tudo vai pela quantas anda minha cabeça naquele determinado dia. Gosto muito de cutucar poderosos, os tais donos do poder, os mandarins dessa cidade e fazer isso não tem preço, ou seja, pago um preço. Já fui processado duas vezes e tudo por algo escrito aqui [no blogue], mas em ambas me safei bem. Eu, assim como todos, tenho um lado e dele não me afasto. Meus assuntos são na defesa desse lado, o que considero correto. Meus temas são versando sobre isso, sobre o mundinho daqui, mas com uma conotação mais global. O cara lê do cara daqui mas percebe que foi sacado para algo muito maior. E os temas vão pintando de acordo com o dia a dia. Privilegio temas mais simples e adoro escrever das pessoas ditas do Lado B daqui e do mundo (AQUINO, 2016) .

Embora as notícias sejam elencadas em um blogue, são raros os textos que utilizam de vários recursos multimídias, destacando-se a utilização de fotografias. O próprio autor também argumenta que a maior dificuldade está no domínio dessas ferramentas.

Vou utilizando o que tenho nas mãos no momento. Nunca fui um bom desbravador de tecnologia internética, apanho muito, mas me aproprio do que consigo alcançar. Se leio algo interessante ali e acho que posso aproveitar, publico e dou meu pitaco final, uma apimentada a mais. Sou um dos únicos que até hoje continua permitindo a publicação de comentários anônimos.

\footnotetext{
${ }^{8}$ Página pessoal do blogueiro Henrique Perazzi de Aquino - www.facebook.com/henrique.perazzideaquino.

${ }^{9}$ Entrevista concedida a este autor no dia 18 de maio de 2016. Ver Apêndice A.
} 
O Mafuá não possui uma página específica nas redes sociais, mas boa parte do conteúdo é divulgado diretamente no perfil do Facebook do autor. Segundo ele, mesmo que de forma desorganizada, esse tem sido o principal canal de retorno e de contato com os leitores dos assuntos publicizados.

Recebo muita provocação, ofensas e até ameaças, mas ainda vale a pena, pois junto vem muita denúncia de gente que para escrever não pode se identificar. E de vez em quando perco também a boa com os inconsequentes, mas tento levar tudo numa boa. A rede é algo para ser utilizado em conjunto, eu gileteio algo daqui, outros colam algo meu e vida que segue. Faço muito isso, mas cito sempre a fonte.

\section{PUBLICIZAÇÃO DE ASSUNTOS PARA EFEITOS COLETIVOS}

Para se reforçar como uma arena pública, o jornalismo hiperlocal produzido nas mídias locativas deve em sua essência, ampliar as dimensões daquilo que é reportado a partir de um recorte local e possibilitar um amplo debate e possíveis dinâmicas, que resultem na mobilização da opinião pública. Um caso recente do Mafuá do HPA está inserido neste contexto. No ano de 2015, em meados do mês de fevereiro, a Prefeitura de Bauru iniciou uma nova reforma na principal e mais antiga praça pública da cidade localizada na área central, a Praça Rui Barbosa. De um montante de mais de R $\$ 500$ mil, as obras foram realizadas pela Secretaria de Obras com parte dos recursos subsidiados pelo Governo Federal com previsão de entrega em quatro meses. O blogue do Mafuá do HPA acompanhou mês a mês as atividades que iam acontecendo na área central no entorno da praça, sempre apontando em seus textos uma visão opinativa autoral e que contemplasse a perspectiva daqueles que de alguma forma conviviam com a obra.

Depois de cumprido o prazo inicial de entrega, a empresa responsável solicitou um aditivo e a entrega se prorrogou por mais quatro meses, com o custo total sendo elevado para mais de R \$ 650 mil. Após o término das obras e a retirada dos tapumes, o público pode enfim, ver como ficou o espaço público com a revitalização. No entanto, de acordo com relatos de populares ao Mafuá do HPA, as mudanças foram poucas, nada muito visível, e a praça continuava a mesma de antes, porém com pintura nova, pastilhas recolocadas e outros reparos de pequeno porte que não justificavam o tempo todo e o valor anunciado pela reforma. $\mathrm{O}$ jornalista responsável pelo Mafuá do HPA relatou as observações dos populares em uma reportagem que denominou de "Alfinetada - Quantos mil gastaram e o que mudou nela? Está tudo igual..." (disponível em: mafuadohpa.blogspot.com.br/2015/11/comendo-pelas-beiradas- 
08.html). Essa reportagem também foi postada no perfil pessoal do jornalista e foi objeto de grande repercussão.

A reportagem pautou os principais meios de comunicação da cidade, sendo estampadas as insatisfações dos populares nos jornais, emissoras de rádio e televisão. O principal jornal de Bauru, o Jornal da Cidade, estampou dias depois uma reportagem de página completa com a pauta (com reprodução em seu site www.jcnet.com.br) e reforçando a cobrança de explicações do poder público. A partir das reportagens, a Comissão de Obras da Câmara Municipal solicitou a documentação, incluindo projeto, licitação, orçamentos, planilhas, ordens de serviço e contrato, relativa à revitalização da Rui Barbosa.

O Mafuá do HPA, com sua característica própria de denunciar e prospectar resultados do poder público continua reportando os acontecimentos que giram em torno da polêmica obra de revitalização. Em abril de 2016, o blogue publicou nota (disponível em: mafuadohpa.blogspot.com.br/2016/04/dicas-147.html) observando uma 'nova reforma', que foi denominada pelo jornalista de recall, meses depois da revitalização. Além de apontar as novas obras como possível consequência daquilo que havia sido questionado em postagens anteriores, o blogue aponta novas denúncias sobre a qualidade do serviço apresentado para o recall.

Quando indagado sobre se considerava que o Mafuá tinha ação direta nos assuntos públicos da cidade, o autor desconversou, mas considerou o fato de muitos o procurarem por causa do blogue para que sejam externadas suas demandas:

Se consegui alguma coisa nesse tempo todo isso se deve por ter sempre trilhado o bom caminho, o acertado. Isso não quer dizer que não piso em falso, nem ando em erradas, pois isso é algo normal para mim, o que digo é que por escrever de tudo, me meter em cada assunto que muitos nem ousam tocar, acredito ter conseguido algo de bom. Numa porcentagem bem pequena, vejo que me respeitam e nem por causa disso me tornei um cidadão mais sério. Estou fora dos enquadramentos ditos normais, ou pelo menos assim me vejo (AQUINO, 2016) ${ }^{10}$.

Em um segundo momento, optou-se por realizar uma pesquisa com os leitores do Mafuá do HPA. Para tanto, foi realizado um questionário público online por meio da ferramenta Google Questionário ${ }^{11}$ com nove questões elaboradas a partir das características apontadas sobre as mídias hiperlocais no Capítulo 3 e que serão apresentadas ao logo desse

\footnotetext{
${ }^{10}$ Entrevista concedida a este autor no dia 18 de maio de 2016. Ver Apêndice A

${ }^{11}$ Disponivel em https://goo.gl/mjeMIb
} 
item. Para a aplicação dos questionários, foi realizado um post público em um grupo de discussão na rede social Facebook onde são publicizados os conteúdos do Mafuá do HPA por meio da atuação de seu autor. A intenção e importância da pesquisa, que poderia ser realizada de modo anônimo, foram explicadas tanto no post quanto no questionário e esperou-se duas semanas para a coleta das respostas (de 20 de junho a 01 de julho de 2016). Ao todo, foram obtidas 108 respostas de distintas localizações de Bauru, o que representa de acordo com dados fornecidos pelo autor do blogue, um total de $15,4 \%$ da sua audiência semanal. De acordo com HPA, o Mafuá do HPA apresenta uma média de 700 leitores distintos por semana comprovados com os dados gerados pela plataforma Blogger, o que dimensiona para em média 100 usuários distintos com acesso aos posts publicados. De acordo com o último censo demográfico em 2010, Bauru possui 343.937 residentes, o que faz com que o Mafuá do HPA apresente apenas $0,20 \%$ de leitores semanais, isso considerando o número bruto e que todos os residentes estão com recursos de acesso pleno. Como não há uma página em rede social específica para o blogue, a medição de audiência fica prejudicada quando consideramos a divulgação dos conteúdos pelo perfil do autor no Facebook, uma vez que o site apenas oferece recursos para a medição de audiências de páginas e não de perfis.

Logo de início, a intenção com as primeiras questões apresentadas foi a de mapear de onde cada resposta estava sendo encaminhada. Para isso, optou-se por trabalhar com a ferramenta Google Maps para criar um mapa interativo que fosse capaz de dar uma visão geral das áreas de influência do Mafuá. A pergunta destinada para inserir o bairro do questionado era a única obrigatória. Cada resposta do questionário, associada a uma pessoa diferente, gerou um ponto distinto no mapa de 01 a $96^{12}$, com localização apontada de forma a apenas gerar um resultado visual, não comprometido com a exatidão espacial, até pelo fato dos voluntários não terem apontado o endereço exato de onde estavam respondendo. $\mathrm{O}$ objetivo do mapa foi ter uma visão de onde estão localizados os leitores do blogue analisado, tendo como ponto de partida que uma mídia hiperlocal precisa estar inserida em um contexto de localidade contracenando com as ideias de pertencimento e identidade, como já descrito anteriormente.

O mapa interativo gerado por meio da ferramenta do Google apresenta focos de usuários que se prontificaram a responder o questionário online, ficando nítido que há uma dispersão do centro (regiões consideradas economicamente mais prósperas) para a periferia (menos prósperas).

\footnotetext{
${ }^{12} \mathrm{O}$ mapa gerado é público e está disponibilizado para consultas no link < https://goo.gl/qU8fDU >
} 
Ao considerarmos apenas os números absolutos das respostas dos questionários, nas cinco primeiras posições aparece uma mescla entre bairros de regiões nobres de Bauru, como Higienópolis ( $1^{\circ}$ lugar com 13 respostas) e Jardim Europa ( $3^{\circ}$ lugar com 8 respostas), e outros bairros considerados populares, como Mary Dota ( $2^{\circ}$ maior número de respostas com 10 questionários) e Geisel ( $5^{\circ}$ maior com 8 questionários). Ao agrupar os bairros em zonas geográficas, conforme estabelecido pelo município, em primeiro lugar em número absoluto de respostas está a Zona Centro-Sul com 52 questionários seguido pela Zona Oeste que aparece em segundo com 23 questionários. A Zona Norte aparece na sequência com 22 questionários seguido pela Zona Leste com 11.

Com essa divisão, evidenciando uma audiência dispersa pelas áreas da cidade, o Mafuá do HPA garante uma legitimação de base popular. Quando voltamos ao mapa interativo elaborado a partir da localização, no qual cada resposta é identificada por um ponto, podemos traçar cinco áreas onde há maior aglomeração, indistintamente dos bairros que compõem cada área (figura 1). Quando traçamos um paralelo entre cada uma das cinco zonas observadas e a divisão geográfica da cidade, três marcações (1, 2 e 3) estão na região centrosul da cidade, um na norte (5) e outra na leste (4), evidenciando que a maioria expressiva está em regiões economicamente nobres da cidade.

A divisão em zonas como realizado anteriormente a partir das respostas dos questionários online se faz necessária diante das características da cidade. De acordo com o último censo demográfico em 2010, Bauru possui 343.937 residentes (sendo 338.184 urbanos e 5.753 rurais), com PIB per capita de $\mathrm{R} \$ 28.976,18$ reais, com renda per capita de $\mathrm{R} \$ 733,33$ reais na área urbana e de $\mathrm{R} \$ 555,00$ reais na área rural; dados que fazem com que o Índice de Desenvolvimento Humano (IDH) seja considerado alto para o país na marca de 0,801 (em uma escala crescente de 0 a 1), que representa o $178^{\circ} \mathrm{IDH}$ nacional e $50^{\mathrm{a}}$ posição no Estado de São Paulo. De acordo com um estudo sobre Índice Gini, que faz a medição da pobreza, Bauru apresenta a marca de 0,55 (em uma escala decrescente de 1 a 0 ), o que faz com o município liste entre as cidades com menor índice de exclusão social. No entanto, Bauru reproduz a desigualdade de distribuição de renda da sociedade brasileira, com 1/5 da população mais pobre com $9 \%$ da renda, enquanto o $1 / 5$ mais rico se apropria de $42 \%$. Tais características, explicam o fato de que a população considerada de menor renda esteja concentrada nas regiões periféricas, afastadas da área central e sul, onde também estão concentradas as deficiências de serviços de infraestrutura urbana, moradia, transporte, educação, saúde, entre outros. Já a zona centro-sul tem como consequência da concentração de renda a oferta ampliada dos recursos públicos. 
De acordo com o Plano Diretor do Município, essas características fazem com que exista um bolsão de riqueza cercado de ampla extensão de exclusão. Ainda de acordo com o documento, a desigualdade na distribuição de renda é diretamente proporcional à da escolaridade na população. Na região centro-sul, a mais rica da cidade, concentra-se a maior incidência de população com maior escolaridade. Ao contrário, nas regiões periféricas reside a maior incidência da população analfabeta, especialmente nas favelas.

Figura 1 - Pontos de aglomeração das respostas do questionário

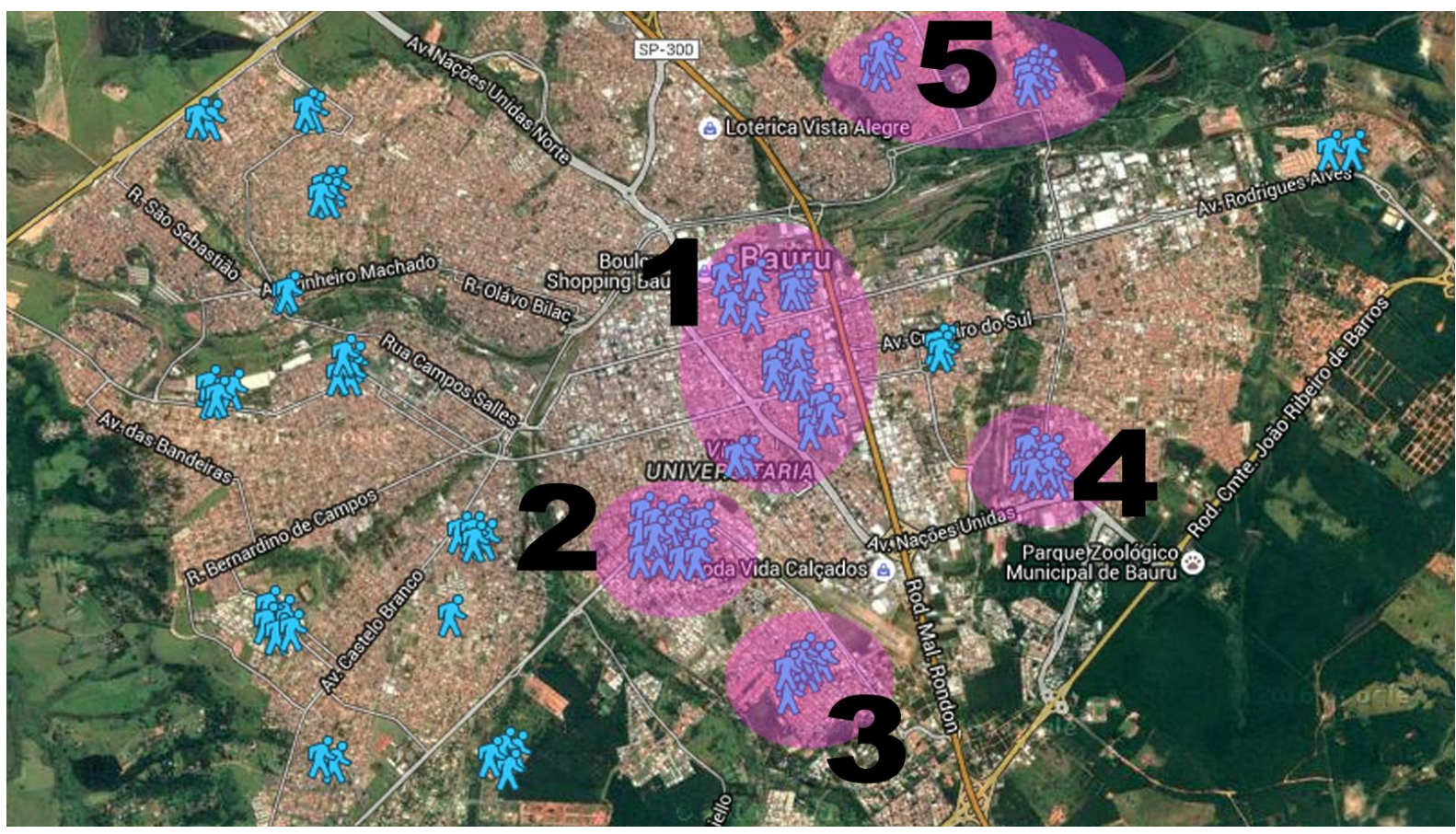

Fonte: Autores (2018).

Embora não haja nenhuma pesquisa na cidade que correlaciona esses dados do IBGE com o acesso à tecnologia e informação, é possível fazer um paralelo com pesquisas em âmbito nacional. Uma pesquisa da Comissão Econômica para a América Latina e o Caribe (Cepal), divulgada em 2015, revelou que somente 1,7\% das casas mais pobres do Brasil têm acesso à internet. Nesse sentido, pode-se afirmar que, muito embora o foco de produção do blogue seja evidenciar as camadas populares, o acesso está centrado em regiões consideradas economicamente mais ricas, podendo afirmar que há uma pulverização do centro-sul para as áreas mais periféricas, como norte, oeste e leste da cidade.

Em relação a forma como o leitor passou a conhecer o blogue analisado, os números absolutos apresentados pelo questionário são muito próximos. A maioria dos usuários $(39,8 \%)$ apontou que conhece o blogue por causa da interação das redes sociais, o que se 
subentende pelo perfil do HPA e do fluxo geral de interação gerado. Em segundo lugar, apareceu que $32,4 \%$ chegaram ao Mafuá por meio de conhecidos e outros 27,8\% a partir do próprio autor.

Quando se faz uma divisão entre as regiões traçadas até agora, considerando as respostas separadas dos entrevistados, percebe-se que a forma como o leitor conheceu o blog vai se alterando. Enquanto que na Zona Centro-Sul 50\% dos entrevistados (26 respostas do total mapeado dos bairros daquela região) disseram que conheceram o blogue pelas redes sociais (contra $26,92 \%$ por conhecidos e $23,07 \%$ pelo próprio autor), na Zona Leste, $54,54 \%$ (6 entrevistados do total considerado) conheceram o Mafuá a partir de seu autor, 18,18\% (2 respostas) nas redes sociais e $27,27 \%$ por conhecidos (3 respostas).

O fato de o Mafuá ser apontado pela maioria dos entrevistados como um site com visão diferenciada, reflete na visão de sua audiência frente aos demais meios de comunicação de Bauru. A maioria dos entrevistados considera o blogue como uma possível fonte alternativa (figura 31) para se informar (47,2\%), enquanto 33,3\% apontaram que preferem se saber sobre os acontecimentos da cidade a partir das postagens realizadas no blogue. Já 17,6\% negaram usar o Mafuá como uma fonte primária de notícia. Se considerarmos aqueles que leem o blogue o considerando como uma fonte alternativa com aqueles que declaram se informar pelas postagens, a audiência passa a ser de 80,5\%.

Quando analisamos esse quadro sob a ótica da divisão por regiões em Bauru, a concentração daqueles que disseram se informar pelo blogue (figura 32) está concentrada na Zona Norte, com 33,33\%, seguido pela Zona Leste (30,5\%), Zona Oeste (25\%) e por último a Zona Centro-Sul com 11,11\%. Percebe-se assim, ao comparar esses números com o absoluto de respostas dos questionários, que as zonas mais periféricas da cidade, embora não sejam separadamente maioria no acesso, são as que utilizam o blogue como um recurso principal de informação.

Esse cenário se altera quando se considera a porcentagem daqueles que apontaram o Mafuá do HPA como uma fonte secundária e alternativa de informação (figura 33). A aglomeração está na Zona Centro-Sul com ampla maioria $(58,82)$, seguido pela Zona Oeste $(23,5 \%)$, Zona Norte $(9,8)$ e Zona Leste $(7,84 \%)$. Esse quadro é muito parecido quando consideramos o grupo que apontou não considerar o Mafuá como fonte de informação sobre os assuntos da cidade (figura 34). Em primeiro lugar aparece os entrevistados da Zona Sul com 57,9\% desse total, seguidos pela Zona Leste $(26,31)$ e Zona Oeste $(15,79 \%)$, sendo que nenhum morador da Zona Norte apontou essa opção. 
O próximo passo foi quantificar quantos dos 108 entrevistados consideram a produção do blogue relevante para a comunidade ou mesmo para a sua rotina individual (figura 35). A ampla maioria, 80 entrevistados $(74,1 \%)$ disseram que consideram relevante ao passo que 15,7\%, apenas 17 entrevistados disseram que não. Do total de respostas, 11 entrevistados $(10,2 \%)$ escolheram a opção de que não saberiam responder.

Retornando ao exercício de fracionar as respostas por regiões/localidades da cidade, é possível apontar que os moradores da Zona Centro-Sul são maioria em apostar que os fatos publicados não são relevantes para o cotidiano da comunidade (70,58\%, ou 12 respostas), embora seja o grupo majoritário quando se considera aqueles que dizem visualizar a relevância $(42,50 \%, 34$ respostas) e daqueles que não souberam opinar $(33,33 \%$, seis respostas). Ainda entre os que consideram relevantes os assuntos (figura 36), 23,75\% são da Zona Norte (19 respostas), 22,5\% da Zona Oeste (18 respostas) e 11,25\% da Zona Leste (nove respostas). Já entre os que não consideram os assuntos reportados como de importância (figura 37), seguem Zona Leste e Zona Oeste, ambas com 11,76\%, e a Zona Norte por último com 5,88\%. Já entre os que não souberam apontar, logo após a frente da Zona Centro-Sul (seis respostas), aparecem a Zona Oeste com 27,27\% (3 respostas) e Zona Norte com 18,18\% (duas respostas).

Sendo assim, ao mesmo tempo em que a Zona Centro-Sul diz reconhecer a relevância do conteúdo publicizado, ela se divide ao dizer que não sabe dimensionar o impacto e que não há nenhuma relevância. Ao mesmo tempo, quando se consideram os números absolutos, pode-se afirmar que a maioria dos cidadãos que acessam o Mafuá do HPA reconhece a importância do conteúdo publicado para a comunidade e para questões e cenários de aspectos individuais. Mesmo somando a quantidade absoluta de questionários que apontaram a não relevância ou não saber de sua existência, os números obtidos nas Zonas Leste (duas respostas), Oeste (cinco) e Norte (três), não ultrapassam o total daqueles que reconhecem a importância do blogue em cada região, sendo esses nove, 18 e 19 respostas respectivamente nas zonas apontas como diagnosticado anteriormente.

Embora o HPA tenha mencionado na entrevista semiestruturada que recebe sugestões de colegas e amigos e busca atendê-las, sendo que muitas vezes recebe pedidos diretos de publicação, as respostas dos questionários apontam que a maioria dos leitores não contribui $(55,6 \%)$, enquanto outros apontaram que raramente fazem contribuições $(16,7 \%)$. Os que disseram que contribuem frequentemente chegaram a $14,8 \%$, enquanto $13 \%$ disseram que gostariam de enviar contribuições, mas que não sabem quais são as formas. 


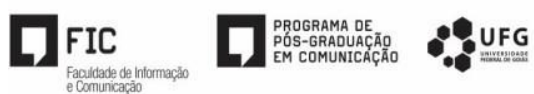

A última pergunta realizada foi sobre as possíveis mudanças que os leitores fariam no blogue. A maioria optou por marcar que aumentariam a frequência de postagens do blogue $(27,8 \%)$. Como o próprio autor apontou, a média do Mafuá é de uma postagem por dia. Em outra abordagem do questionário, os leitores foram indagados sobre como avaliam a produção dos conteúdos divulgados pelo Mafuá: 55,6\% apontaram como boa e outros 41,7\% como excelente, ou seja, embora em quantidade insatisfatória, a qualidade da produção tem aprovação de $97,3 \%$ dos leitores.

Logo na sequência sobre as mudanças, com uma porcentagem bem próxima (25\%) apareceram aqueles que fariam melhores adaptações na estrutura do site. Outros 19,4\% sugerem novos estilos de quadros e 15,7\% gostariam que as postagens apresentassem outros recursos, tais como imagem, links e vídeos. A vinculação com as redes sociais foi a opção escolhida por $11,1 \%$.

\section{ALGUMAS CONSIDERAÇÕES}

Diante dos dados coletados pelo questionário online e apresentados anteriormente, podemos inferir que o Mafuá do HPA mesmo com uma audiência bem inexpressiva diante da população absoluta de Bauru (infelizmente não há dados oficiais dos usuários de internet da cidade), com uma dinâmica específica de produção baseada nos anseios de seu idealizador, possui uma área de atuação definida. A maioria dos leitores do blogue está concentrada em regiões consideradas abastadas de Bauru, como a Zona Centro-Sul, embora o vínculo com a comunidade seja ressaltado quando se olha a audiência presente nas periferias da cidade; o que pode ser justificado pelo privilégio editorial por assuntos dessas regiões. Como aponta o autor no blogue e na entrevista realizada, o foco do blogue é a produção de conteúdos que em sua visão, são desconsiderados pela mídia corporativa da cidade. Isso faz com que, mesmo sendo minoria entre a audiência, os cidadãos das regiões periféricas considerem o blogue como uma fonte de notícia sobre os assuntos locais, chegando a ter impacto no cotidiano da comunidade onde estão inseridos ou mesmo em sua rotina. Ao passo que entre os cidadãos da Zona Centro-Sul, o blogue acaba sendo desconsiderado como um meio informativo sobre os assuntos locais e passa a ser vislumbrado como um meio de comunicação que traz uma visão alternativa àquilo que é produzido pela mídia corporativa.

Muito embora o blogue traga uma produção descentralizada de conteúdo, com a ausência de esquemas laborais profissionais como os visualizados em corporações com esse intuito, a audiência é considerada, como mesmo apontou o responsável. No entanto, as formas 


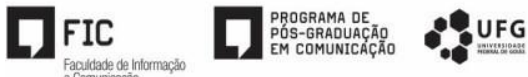

como essas considerações podem ser encaminhadas acabam sendo pouco disseminadas. Muitos dos conteúdos sugeridos acabam sendo realizados porque o leitor conhece o responsável pelo blogue ou mantém algum tipo de relação direta. Pelas respostas apresentas, tanto os cidadãos das regiões abastadas como os de zonas mais periféricas encontram dificuldades para efetivar a sua participação, seja porque desconhece que essa seja possível ou por não saberem quais são os caminhos para tanto. A frequência de atualização com conteúdo inédito é uma possível mudança apontada pela maioria dos leitores, o que evidencia uma audiência que anseia por conteúdos locais com maior frequência.

O fato do Mafuá do HPA assumir características de arena pública pode-se aqui apontar que, em primeira análise, estar primordialmente atrelado a uma comunidade (é um blogue destinado a apresentar assuntos do cotidiano bauruense em suas várias áreas de abrangência), com uma concepção de mídia oriunda no seio dessa comunidade e que apresenta um potencial de interação com a sociedade civil nela presente. Embora a população local tenha uma ínfima participação nos processos de gerenciamento do fluxo do blogue (muitas desconhecem os caminhos para ou mesmo não sabem que há essa possibilidade), esse cria laços com essa comunidade ao tentar captar as demandas locais, problematizá-las e publicizá-las no espaço hiperlocal. Muito embora a figura do seu criador seja central para a manutenção da produção e do fluxo, o blogue, na prerrogativa de uma arena pública, acaba por captar os interesses, as diversas opiniões que muitas vezes só estão presentes nas esferas privadas, e os discute por meio de uma redação postada no blogue, fazendo com que essas sejam irradiadas à esfera pública. O caráter do Mafuá do HPA como uma arena pública seria intensificado se o autor criasse mecanismos mais claros e explícitos para a população participar e debater aquilo que é problematizado. A independência do Mafuá do HPA face aos centros políticos e econômicos da cidade possibilita, tal como acredita Habermas (2006), a ampliação democrática da participação e decisão na Esfera Pública. Quando a interação com os leitores for plena e ativa, haverá um processo de empoderamento para que esses participem e respondam a um discurso público (HABERMAS, 2006).

Com apenas nove anos de atuação, pode se inferir que o Mafuá ainda anseia por sua própria identidade vinculada às características de um local ou mesmo de um espaço hiperlocal. Como ponto de partida, pode-se dizer que o projeto cidadão é um embrião de eventuais possibilidades que possam ser realizadas na cidade ou em comunidade mediante as características hiperlocais até aqui traçadas.

Falta ao projeto de Henrique Perazzi de Aquino um padrão de atuação que possa intensificar sua aproximação com a comunidade e fazer com que essa interação atinja 
patamares de interação contínua; podendo dizer que pode ter uma busca por algum modelo de sustentação (financeiro para justificar mudanças na estrutura, no aumento do fluxo de produção ou mesmo na capacitação de seu idealizador para eventuais reestruturações) que fuja dos anseios particulares de seu idealizador para que todos os nichos o considerem um ponto de referência sobre os acontecimentos locais. Por ser uma mídia online, o blogue tem suas potencialidades superestimadas, seja pelo pouco uso de recursos tecnológicos fornecidos pelo ciberespaço ou mesmo na adoção de características de fluxos noticioso jornalístico como outros meios hiperlocais tem adotado visando realçar elementos utilizados na construção de representações sociais nos contextos econômico, político, histórico e sociocultural.

\section{REFERÊNCIAS}

BARBOSA, Suzana. Jornalismo convergente e continuum multimídia na quinta geração do jornalismo nas redes digitais. Notícias e Mobilidade. O Jornalismo na Era dos Dispositivos Móveis. Covilhã, PT: Livros LabCOM, 2013, p. 33-54.

DOURADO, Mariana. A Esfera Pública no Jornalismo Cidadão Online Refletindo a reconfiguração do conceito de Habermas nas práticas colaborativas da notícia. In: Biblioteca Online de Ciências da Comunicação (BOCC). 2010. Disponível em: http://www.bocc.ubi.pt/_esp/autor.php?codautor=1806\#topo. Acesso em: 03 set. 2018.

HABERMAS, J. Further reflections on the Public Sphere. In: CALHOUN, Craig (Ed.), Habermas and the public sphere. Cambridge, MA/London: MIT Press, 1997.

HABERMAS, J. Mudança estrutural da esfera publica: investigacoes quanto a uma categoria da sociedade burguesa. Rio de Janeiro: Tempo Brasileiro, 1984.

KOVACH, B; ROSENSTIEL, T. Os elementos do jornalismo: o que os jornalistas devem saber e o público exigir. São Paulo: Geração Editorial, 2003.

LEMOS, C. E. B.; PEREIRA, R. M. Jornalismo hiperlocal no contexto multimídia: um relato da experiência do jornal-laboratório Contramão Online. Intercom - Sociedade Brasileira de Estudos Interdisciplinares da Comunicação. 2011. Disponível em: <http://www.intercom.org.br/papers/regionais/sudeste2011/resumos/R24-0588-1.pdf>. Acesso em 20 fev. 2018.

LOPEZ GARCÍA, X. Repensar o jornalismo de proximidade para fixar os media locais na sociedade glocal. Comunicação e Sociedade: Universidade do Minho, Braga, v. 4, n. 1, p. 199-206, 2002.

MARCONDES, V. Novas tecnologias de conexão e o futuro da esfera pública. In: CONGRESSO BRASILEIRO DE CIÊNCIAS DA COMUNICAÇÃO DA REGIÃO SUL, 8., 2007, Passo Fundo, RS. Anais... Passo Fundo, RS: Intercom, 2007. Disponível em:< 
http://www.intercom.org.br/papers/regionais/sul2007/resumos/R0195-1.pdf>. Acesso em: 03 set. 2018.

METZGAR, E.; KURPIUS, D.; ROWLEY, K. Defining Hyperlocal Media: Proposing a Framework for Discussion. In: ANNUAL MEETING OF THE INTERNATIONAL COMMUNICATION ASSOCIATION, 2010. Singapore: Suntec Singapore International Convention \& Exhibition Centre, Jun 22, 2010. Disponível em http://citation.allacademic.com/meta/p404999_index.html. Acesso em: 23 fev. 2018.

MORAES, D.; RAMONET, I.; SERRANO, P. Mídia, poder e contrapoder: da concentração monopólica à democratização da informação. São Paulo: Boitempo/FAPERJ, 2013.

PORTO-GONÇALVES, Carlos Walter. A nova questão agrária e a reinvenção do campesinato: o caso do MST. Geografias (UFMG), v. 1, n. 1, p. 7-25, 2005.

RAMOS, M. C.; SANTOS, S. dos. Políticas de Comunicação: buscas teóricas e práticas. São Paulo: Paulus, 2007.

RIBEIRO, Jorge Claudio. Sempre alerta: condições e contradições do trabalho jornalístico. Olho Dágua: Brasiliense, 1994.

VIZEU, A.; ROCHA, H.; MESQUITA, G. O Cidadão como Coprodutor da Notícia: Novos Desafios ao Jornalismo. CONGRESSO BRASILEIRO DE CIÊNCIAS DA

COMUNICAÇÃO 33. 2010, Caxias do Sul. Anais... Caxias do Sul: Intercom, 2010. 